NOTE

\title{
Antipredatory secosterols from the octocoral Pseudopterogorgia americana
}

\author{
Rosângela de A. Epifanio ${ }^{1, *}$, Lenize F. Maia ${ }^{1,4}$, Joseph R. Pawlik ${ }^{2}$, William Fenical ${ }^{3}$ \\ ${ }^{1}$ Instituto de Química, Universidade Federal Fluminense, Campus do Valonguinho, 24020-005, Niterói, Rio de Janeiro, Brazil \\ ${ }^{2}$ Center for Marine Science, University of North Carolina Wilmington, Wilmington, North Carolina 28409, USA \\ ${ }^{3}$ Center for Marine Biotechnology and Biomedicine, Scripps Institution of Oceanography, University of California, San \\ Diego, La Jolla, California 92093-0204, USA
}

${ }^{4}$ Present address: Departamento de Bioquímica Médica, ICB, CNRMN, Universidade Federal do Rio de Janeiro, Rio de Janeiro 21941-590, Brazil

\begin{abstract}
The chemical defense of the Caribbean octocoral Pseudopterogorgia americana was investigated using feeding assays performed in aquaria and in situ with a natural assemblage of predatory fishes. Using a bioassay-guided scheme, crude extracts, fractions and pure compounds were incorporated into palatable foods and tested. Only the secosterol fraction deterred fish feeding. Two secosterols were identified from the bioactive fraction by spectroscopic methods and comparison with literature data: 9,11-secogorgosterol (Compound 1) and 9,11-secodinosterol (Compound 2), both of which have been previously described from Pseudopterogorgia spp. Our results suggest that symbiont-produced gorgosterol and dinosterol are oxidized by the coral host to C-ring secosterols, which then provide a chemical defense to both coral and alga.
\end{abstract}

KEY WORDS: Gorgonaceae $\cdot$ Octocorallia $\cdot$ Pseudopterogorgia americana $\cdot$ Secosterols $\cdot$ Feeding deterrents $\cdot$ Chemical defense

\section{INTRODUCTION}

Gorgonian octocorals, the sea whips and sea fans, are a group of marine cnidarians that thrive in tropical to warm temperate oceans, being most abundant and diverse in shallow Caribbean waters. Despite their relative abundance on coral reefs, habitats characterized by high levels of predation and nutrient scarcity, octocorals seem to be free of predation by generalist fish predators because of secondary metabolites that provide a chemical defense (O'Neal \& Pawlik 2002). Octocoral chemical defenses have been the subject of investigations in the Caribbean (O'Neal \& Pawlik 2002 and references cited therein) and in western North and South Atlantic waters (Epifanio et al. 2000 and references cited therein). While these studies revealed that most gorgonians contain chemical defenses, only a limited number of specific metabolites were demonstrated to provide deterrent effects (Epifanio et al. 2000 and references cited therein).

Secondary metabolites isolated from Pseudopterogorgia americana include 9,11-secogorgosterols, polyhydroxy- and 9,11-secodinosterols, $\beta$-gorgonene, germacrane, guaiane and bisabolane sesquiterpenes, phospholipid fatty acids and an imidazole betaine (Epifanio et al. 2007). Although crude extracts of $P$. americana proved to be deterrent in aquarium assays using generalist fish predators, the metabolites responsible for this activity were not identified (O'Neal \& Pawlik 2002). In the present study we report on the isolation and identification of the antifeedant compounds from $P$. americana. 


\section{MATERIALS AND METHODS}

General procedures. High-performance liquid chromatography (HPLC) was carried out using a semipreparative silica gel Dynamax column $(15 \mathrm{~cm}$ length, $10 \mathrm{~mm}$ i.d.), a Waters Model M6000 pump and a Waters R401 differential refractometer. Nuclear magnetic resonance (NMR) spectra were recorded in $\mathrm{CDCl}_{3}$ solution on a Varian Unity $500 \mathrm{MHz}$ spectrometer. Infrared radiation (IR) spectra were recorded on a Perkin-Elmer Model 1600 (FTIR) spectrometer. Mass measurements were registered on a HP 5989A spectrometer. Isolation procedures were monitored by employing thin-layer chromatography (TLC) on precoated silica gel plates (Merck, Kieselgel 60 F-254) through UV inspection and $\mathrm{H}_{2} \mathrm{SO}_{4}$ /heat.

Study sites and octocoral collection. This study was performed at Crooked Island and Little San Salvador Island, Bahamas, during an expedition onboard the RV 'Columbus Iselin' in the summer of 1993. Approximately 150 colonies of Pseudopterogorgia americana were collected by SCUBA at 15 to $20 \mathrm{~m}$ depth. The colonies were labeled and air-dried for $2 \mathrm{~h}$. A small amount of each colony was extracted with $\mathrm{CH}_{2} \mathrm{Cl}_{2}$, and the extracts were compared by TLC analysis in order to group them into 2 different chemotypes: A and B. Type B was further identified as $P$. americana by Dr. Frederick M. Bayer (National Museum of Natural History, Smithsonian Institution).

Extracts, fractions and pure compounds from Pseudopterogorgia americana. Gorgonian tissues from 52 colonies $(500 \mathrm{ml})$ were cut into small pieces and extracted with a mixture of methanol/dichloromethane (1:1, once) and pure dichloromethane (twice). The extracts were combined and evaporated under reduced pressure to produce a brownish gum. After separation of a $60 \mathrm{ml}$ corresponding amount for field assays, the remaining crude extract was fractionated by silica gel vacuum chromatography, employing a gradient ranging from 0 to $100 \%$ of ethyl acetate in isooctane to yield 9 fractions $\left(F_{1}\right.$ to $\left.F_{9}\right)$. The fractions were recombined into 3 major fractions $\left(F_{A}\right.$ to $\left.F_{C}\right)$ based upon their TLC similarity. The most polar fraction $\left(\mathrm{F}_{\mathrm{C}}\right)$ was further purified by normal phase HPLC using mixtures of isooctane and ethyl acetate, yielding in order of elution, Compounds 2 and 1, which were identified by spectroscopic methods (IR, MS, ${ }^{1} \mathrm{H}$ and ${ }^{13} \mathrm{C}$ NMR) and comparison with literature data (He et al. 1995).

Laboratory palatability assays. Aquarium feeding assays were performed as described in Pawlik et al. (1995) using the carnivorous wrasse Thalassoma bifasciatum, which were captured on the same reefs from which gorgonians were collected. Food pellets were prepared by mixing the test solution (crude extracts or semi-purified fractions) with a mixture of sodium alginate $(0.4 \mathrm{~g}), 10 \mathrm{ml}$ of water and squid paste $(1 \mathrm{~g})$. The concentration used for test compounds was calculated on the basis of the natural volumetric amount found in fresh gorgonian tissues. Control pellets were treated with the same amount of solvent $\left(\mathrm{CH}_{2} \mathrm{Cl}_{2}\right)$ used in treated pellets. After hardening with $\mathrm{CaCl}_{2}$ solution, the pellets were cut and offered in control-treated pairs, 1 pellet at time, to fish at the top of the aquarium. Ten replicates were made of each test solution, using 10 different aquaria with 3 fishes each. A food pellet was considered unpalatable when the fish rejected it 3 or more times. A significant difference between the number of treated and control pellets eaten was determined for an individual 10 replicate assay if 4 or more pellets were rejected $(\mathrm{p} \leq 0.043$, 1-tailed test, see Pawlik et al. 1995).

Field palatability assays. Field assays were performed at Little San Salvador Island and Sweetings Cay, Bahamas. Food strips were prepared using the previously established methodology (e.g. Pawlik \& Fenical 1992), involving a combination of $2.5 \mathrm{~g}$ carrageenan, $60 \mathrm{ml}$ of water and $20 \mathrm{ml}$ commercial tuna fish puree packed in oil. Crude gorgonian extract and fractions were volumetrically reconstituted in a matrix of carrageenan at the same concentration as they occurred in the fresh gorgonian tissues. For each experiment, 20 treated and 20 control strips $(1.0 \times 0.16$ $\times 5.0 \mathrm{~cm}$ each) were arranged in pairs and attached to 20 ropes. The ropes were anchored slightly above the bottom near to the same site where gorgonians were collected. Within $3 \mathrm{~h}$, the ropes were retrieved and the amount of each strip eaten was measured. During the experiments several fishes were observed feeding on the test strips (e.g. Halichoeres bivittatus, H. macupilina, Eupomacentrus partitus, Bodianus rufus and, the most abundant, Thalassoma bifasciatum). The Wilcoxon paired-sample test was used to analyze the results (Pawlik \& Fenical 1992).

\section{RESULTS}

Approximately 150 colonies of morphologically similar specimens of Pseudopterogorgia americana were collected. TLC analysis of the organic crude extracts led us to divide the specimens into 2 chemotypes, A and $\mathrm{B}$, with those in Chemotype $\mathrm{B}$ having 1 additional polar compound not found in A. Crude extracts of specimens from both chemotypes were separately tested in aquaria, and indicated that Chemotype B was more deterrent than A (Fig. 1). The crude extracts of each chemotype were derived from several colonies, and therefore represented an average concentration of secondary metabolites for that chemotype, as indicated 


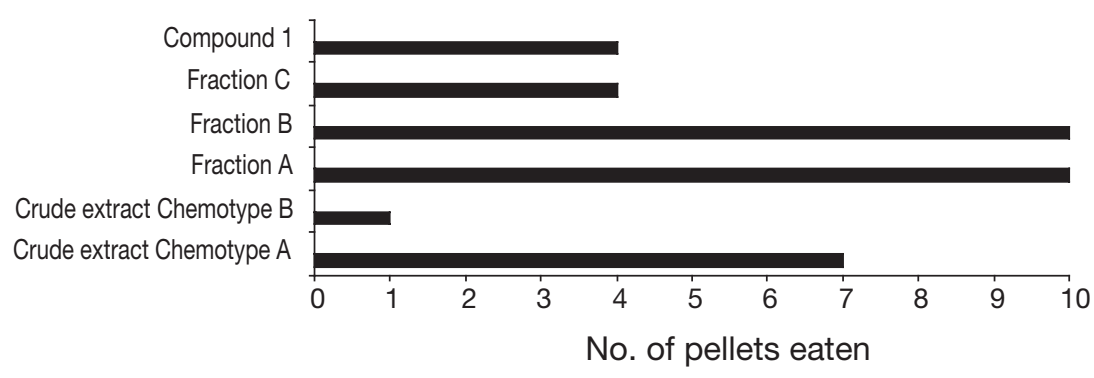

Fig. 1. Consumption by Thalassoma bifasciatum of food pellets containing crude organic extract and semi-purified fractions from Pseudopterogorgia americana; extracts were considered deterrent if the number of pellets eaten was $\leq 6$
Extracts, fractions and pure compounds were weighed after returning to the laboratory, and HPLC and ${ }^{1} \mathrm{H}-\mathrm{NMR}$ of the samples were done to determine the concentrations used in field assays (Fig. 3). The concentration of Compound 1 in gorgonian tissue was $\sim 4.5 \mathrm{mg} \mathrm{ml} \mathrm{m}^{-1}$, slightly higher than what was used in field assays $\left(\sim 4.0 \mathrm{mg} \mathrm{ml}^{-1}\right)$. On the other hand, the concentration of Compound 2 used in field assays was $\sim 25 \%$ (pure) and $\sim 22 \%$ (combined $1+2$ ) of by TLC analysis performed on each individual colony. The specimens grouped in Chemotype B were further identified as $P$. americana. Field assays performed with the crude extracts of Chemotype $B$ revealed that they deterred a natural assemblage of fish consumers $(\mathrm{p}<$ 0.0001 ) and corroborated the laboratory results (see Fig. 3).

Fractions of the crude extract of Chemotype B were then tested in the aquarium assay as a guide to subsequent purification of active compounds. Initially, none of the 9 fractions obtained from silica gel vacuum chromatography purification showed feeding deterrent activity when assayed in aquaria (all the treated pellets were eaten by fishes). This was likely because the active metabolites were diluted into several fractions. The fractions were then combined into 3 according to their polarities, and the assays were repeated, revealing significant activity in Fraction C (Fig. 1). Purification of Fraction $\mathrm{C}$ by normal-phase HPLC yielded a major compound identified as 9,11-secogorgosterol (Compound 1), and a minor component, 9,11-secodinosterol (Compound 2); the structures of both compounds are given in Fig. 2.

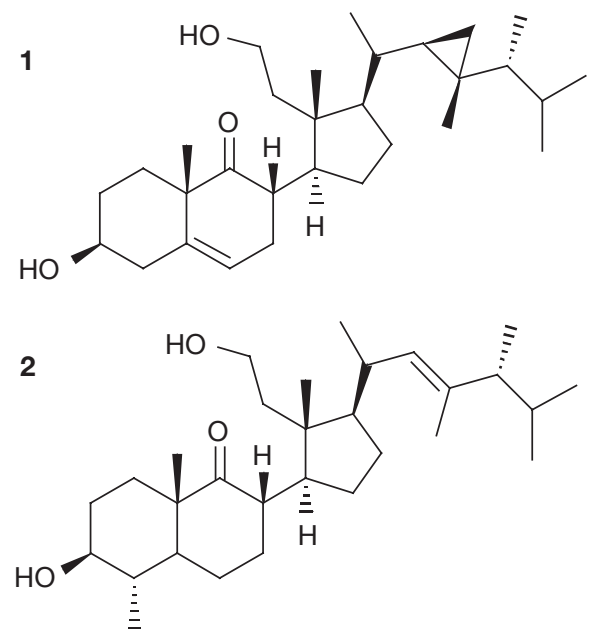

Fig. 2. Pseudopterogorgia americana. Structures of isolated secosterols the natural concentration found in the gorgonian $\left(\sim 1.12 \mathrm{mg} \mathrm{ml}^{-1}\right)$.

\section{DISCUSSION}

It is known that some marine organisms contain 5, 6-, $9,11-, 9,10-, 8,9-, 8,14-$, or 13,17-secosterols, but their biological functions remain unknown (Sica \& Musumeci 2004). Sterols are often considered to be primary metabolites, components of cell membranes or as being involved in cell signaling, but they are otherwise thought to be devoid of ecological properties. In fact, none of these compounds have been tested in ecologically relevant laboratory or field assays in the past. Using an assay of limited ecological relevance, herbasterol, a polyhydroxylated 9,11-secocholestane isolated from the sponge Dysidea herbacea, was found to be toxic to the freshwater goldfish (Capon \& Faulkner 1985). 9,11-secosterols are relatively rare in nature, and some have been isolated from octocorals, sponges

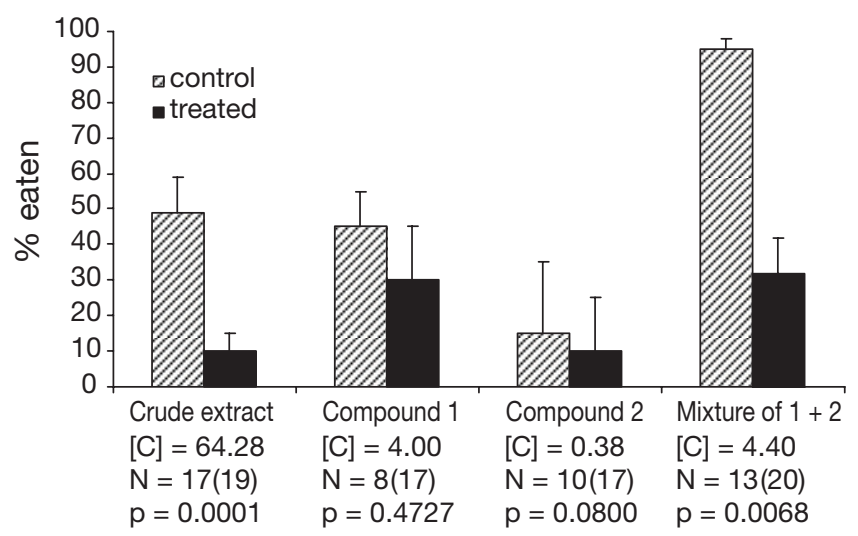

Fig. 3. Consumption by co-occurring fishes of paired carrageenan-based food strips with (treated) and without (control) Pseudopterogorgia americana Chemotype B crude extracts and isolated compounds. Concentration [C] is in $\mathrm{mg} \mathrm{ml}^{-1}$. Error bars: $+\mathrm{SD}_{i} \mathrm{~N}$ : no. of paired treated and control strips used in statistical analyses; (in parentheses no. of pairs retrieved of 20 deployed); p: probability calculated with the Wilcoxon paired sample test, 1-tailed 
and an ascidian. With the exception of an epoxy-9,11secogorgosterol isolated from Lobophytum sp., 9,11secogorgosterols and 9,11-secodinosterols have been previously isolated only from the genus Pseudopterogorgia (Sica \& Musumeci 2004 and references cited therein). Despite the activity observed for pure Compound 1 in aquarium assays (Fig. 1), Compounds 1 and 2 were not deterrent to reef fishes in field experiments when assayed separately, but were deterrent in combination, suggesting a synergistic effect (Fig. 3).

In the gorgonians, the complex mixtures of sterols found in most species reflect a dietary accumulation, de novo biosynthesis and, if present, a sterol contribution from their endosymbiotic dinoflagellates (zooxanthellae). Culture experiments have shown that some zooxanthellae have the ability to produce gorgosterol and dinosterol (Withers et al. 1982). As a consequence, the secosterols in Pseudopterogorgia americana would appear to originate from the zooxanthella endosymbionts. Kerr et al. (1996) showed that enzyme preparations of whole $P$. americana colonies were capable of the transformation of radiolabeled gorgosterol into labeled 9,11-secogorgosterol (Compound 1). Hence, it appears that the chemical defense of $P$. americana results from symbiont-produced gorgosterol and dinosterol, oxidized by the host animal to C-ring secosterols, which then provide protection to both the gorgonian coral and endosymbiotic alga.

Acknowledgements. We thank Dr. Frederick Bayer, National Museum of Natural History Smithsonian Institution, for identification of the gorgonian, and the staff at the Mass Spectrometry Center, University of California at Riverside for providing HRMS. Collaborative research between the USA and Brazil was supported by joint and individual grants from

Editorial responsibility: Howard Browman (Associate Editorin-Chief), Storebø, Norway the International Division of the National Science Foundation (NSF, USA) and the Conselho Nacional de Pesquisas (CNPq, Brazil).

\section{LITERATURE CITED}

Capon RJ, Faulkner DJ (1985) Herbasterol, an ichthyotoxic 9,11-secosterol from the sponge Dysidea herbacea. J Org Chem 50:4771-4773

Epifanio RA, Maia LF, Fenical W (2000) Chemical defenses of the endemic Brazilian gorgonian Lophogorgia violaceae Pallas (Octocorallia, Gorgonaceae). J Braz Chem Soc 11: 584-592

Epifanio RA, Maia LF, Pawlik JR, Fenical W (2007) A new feeding deterrent secosterol from the octocoral Pseudopterogorgia americana. J Braz Chem Soc (in press)

He H, Kulanthaivel P, Baker BJ, Kalter K, Darges J, Cofield D, Wolff L, Adams L (1995) New antiproliferative and antiinflammatory 9,11-secosterols from the gorgonian Pseudopterogorgia sp. Tetrahedron 51:51-58

Kerr RG, Rodrigues LC, Kellman J (1996) A chemoenzymatic synthesis of 9(11)-secosteroids using an enzyme extract of the marine gorgonian Pseudopterogorgia americana. Tetrahedron Lett 37:8301-8304

O'Neal W, Pawlik JR (2002) A reappraisal of the chemical and physical defenses of Caribbean gorgonian corals against predatory fishes. Mar Ecol Prog Ser 240:117-126

Pawlik JR, Fenical W (1992) Chemical defense of Pterogorgia anceps, a Caribbean gorgonian coral. Mar Ecol Prog Ser 87:183-188

Pawlik JR, Chanas B, Toonen RJ, Fenical W (1995) Defenses of Caribbean sponges against predatory reef fish. I. Chemical deterrency. Mar Ecol Prog Ser 127:183-194

Sica D, Musumeci D (2004) Secosteroids of marine origin. Steroids 69:743-756

Withers NW, Kokke WCMC, Fenical W, Djerassi C (1982) Sterol patterns of cultured zooxanthellae isolated from marine invertebrates: synthesis of gorgosterol and 23-desmethylgorgosterol by aposymbiotic algae. Proc Natl Acad Sci USA 79:3764-3768

Submitted: December 2, 2005; Accepted: May 30, 2006 Proofs received from author(s): December 19, 2006 